\title{
4,4'-Bond secalonic acid D targets SP cells and inhibits metastasis in hepatocellular carcinoma
}

\author{
LI CHEN $^{1,2}$, MIAO-MIAO CHENG ${ }^{2}$, YA-PING LI ${ }^{2}$, SHAO-FENG LIN ${ }^{1,3}$, \\ QIU-HONG ZHENG ${ }^{1}$ and QIN-YING LIU ${ }^{1}$ \\ ${ }^{1}$ Fujian Provincial Key Laboratory of Tumor Biotherapy, Fujian Cancer Hospital and Fujian Medical University \\ Cancer Hospital, Fuzhou, Fujian 350014; ${ }^{2}$ Institute of Biomedical and Pharmaceutical Technology, \\ Fuzhou University, Fuzhou, Fujian 350002; ${ }^{3}$ Department of Thoracic Surgery, Fujian Cancer Hospital and \\ Fujian Medical University Cancer Hospital, Fuzhou, Fujian 350014, P.R. China
}

Received September 17, 2019; Accepted March 6, 2020

DOI: $10.3892 / \mathrm{mmr} .2020 .11055$

\begin{abstract}
The existence of cancer stem cells (CSCs) is considered to be the main reason for chemoresistance, metastasis and the ultimate failure of treatment in hepatocellular carcinoma (HCC). However, there are a few chemical agents that may inhibit CSCs. The present study identified that 4,4 '-bond secalonic acid D (4,4'-SAD), a compound isolated from the marine-derived fungus Penicillium oxalicum, inhibited the growth of side population (SP) cells isolated from human liver cancer cell lines PLC/PRF/5 and HuH-7 by attenuating the expression of ATP-binding cassette superfamily G member 2 . Furthermore, the results of wound healing, Transwell, western blotting and reverse transcription-quantitative PCR assays demonstrated that 4,4'-SAD suppressed the invasion and migration of SP cells by downregulating matrix metallopeptidase 9 (MMP-9) and upregulating the antagonist tissue inhibitor of metalloproteinases 1 in vitro. Moreover, in vivo study results found that 4,4'-SAD had anti-lung metastasis efficacy via the decrease of MMP-9 expression in the H22 HCC model of Kunming mice. Therefore, the present study identified the potential of 4,4'-SAD as a promising candidate for the treatment of advanced liver cancer.
\end{abstract}

Correspondence to: Dr Qin-Ying Liu, Fujian Provincial Key Laboratory of Tumor Biotherapy, Fujian Cancer Hospital and Fujian Medical University Cancer Hospital, 420 Fuma Road, Fuzhou, Fujian 350014, P.R. China

E-mail: liuqinyingbio@163.com

Abbreviations: CSCs, cancer stem cells; 4,4'-SAD, 4,4'-bond secalonic acid D; SP, side population; HCC, hepatocellular carcinoma; ABC, ATP binding cassette; SAD, secalonic acid D; NSP, non-side population; MMPs, matrix metalloproteinases; ECM, extracellular matrix; TIMPs, tissue inhibitor of metalloproteinases

Key words: 4,4'-bond secalonic acid D, SP cells, metastasis, hepatocellular carcinoma, matrix metalloproteinase 9, ATP-binding cassette superfamily G member 2

\section{Introduction}

Reports from the World Health Organization have indicated that hepatocellular carcinoma (HCC) is one of the leading causes of cancer-related mortality worldwide (1). Although at the beginning treatments can partially or completely shrink tumors, relapse and metastasis lead to treatment failure due to the existence of cancer stem cells (CSCs) $(2,3)$. Moreover, cells isolated by fluorescence-activated cell sorting techniques based on Hoechst 33342 efflux are known as side population (SP) cells and harbor CSCs properties, such as self-renewal and multipotential differentiation (4). The most significant feature of SP cells is their ability to discharge Hoechst 33342 from cells due to the high expression of ATP binding cassette (ABC) transporter proteins (5). Similar to CSCs, SP cells lead to drug-resistance, tissue invasion and metastasis formation (6-8), but only a few chemotherapeutic drugs can target SP cells.

It has been shown that 4,4'-bond secalonic acid D $\left(4,4^{\prime}-\mathrm{SAD}\right)$ is an antitumor bioactive substance of secondary metabolites produced by a marine-derived fungus [Penicillium (P.) oxalicum] (9). Furthermore, its analog, SAD, was isolated in 1969 (10). Previous studies have revealed the antitumor, anti-angiogenic, proapoptotic and antiproliferative potentials of SAD (11-13). Zhang et al (13) and Hu et al (14) both showed that $\mathrm{SAD}$ induces the degradation of $\mathrm{ABC}$ superfamily G member 2 (ABCG2) by activating calpain-1 in SP cells and decreasing the percentage of SP cells in lung cancer. Moreover, the authors' previous study identified that 4,4'-SAD significantly inhibits tumor growth via a caspase-dependent pathway (9). However, the role of 4,4'-SAD in regulating SP cells remains unknown.

The present results suggested that the selected SP cells from human liver cancer cell lines PLC/PRF/5 and HuH-7 were sensitive to 4,4'-SAD as the ABCG2 expression of SP cells was suppressed by 4,4'-SAD. Furthermore, it was found that 4,4'-SAD had significant antimetastatic effects by downregulating matrix metalloproteinase 9 (MMP-9) and upregulating its antagonist tissue inhibitor of metalloproteinases 1 (TIMP-1) in vitro and in vivo. Collectively, the present results may facilitate the development of novel treatments for liver cancer with drug resistance, recurrence and metastasis. 


\section{Materials and methods}

Preparation of 4,4'-SAD. The fungus P.oxalicum was purified from marine sediments collected from the southeast coastal region of China and identified through internal transcribed spacer analysis by Beijing Sunbiotech Co. Ltd. The specimen was preserved in the China Center for Type Culture Collection (preservation no. CCTCC M2013714). 4,4'-SAD was prepared after the fermentation and extraction of $P$. oxalicum and successive purification by chromatographic techniques; the detailed procedure was described in the authors' previous study (9). The structure of 4,4'-SAD is shown in Fig. 1A.

Culture of cell lines. PLC/PRF/5 and HuH-7 liver cancer cell lines were purchased from the Shanghai Cell Resource Center. The murine H22 hepatoma cell line was obtained from the Cancer Metastasis Alert and Prevention Center, Fuzhou University. All cell lines were cultured in RPMI-1640 (Hyclone; GE Healthcare Life Sciences) or DMEM (Hyclone; GE Healthcare Life Sciences) supplemented with $10 \%$ FBS (Hyclone; GE Healthcare Life Sciences) at $37^{\circ} \mathrm{C}$ in a $5 \%(\mathrm{v} / \mathrm{v}) \mathrm{CO}_{2}$ humidified atmosphere.

Animals. A total of 32 female Kunming (KM) mice (weight, 18-20 g; age, 6 weeks) were purchased from Minhou County Wu Experimental Animal Trade Co., Ltd. The mice were maintained under controlled conditions at $19-23^{\circ} \mathrm{C}$ and $40-60 \%$ humidity, with a 12-h light/dark cycle and free access to drinking water and food. Animal experiments were approved by the Animal Care and Use Committee of the Institute of Biomedical and Pharmaceutical Technology (Fuzhou University), according to the Guide for the Care and Use of Laboratory Animals (15). All mice were euthanized with an overdose of sodium pentobarbital $(150 \mathrm{mg} / \mathrm{kg}$; intraperitoneally).

SP cell detection and isolation by flow cytometry. Cells were harvested, washed with PBS and suspended at $1 \times 10^{6}$ cells $/ \mathrm{ml}$ in Hank's balanced salt solution supplemented with 3\% FBS and $10 \mathrm{mM}$ HEPES. Cells were incubated at $37^{\circ} \mathrm{C}$ for $90 \mathrm{~min}$ with $15 \mu \mathrm{g} / \mathrm{ml}$ Hoechst 33342 (Sigma-Aldrich; Merck KGaA) alone or in the presence of $50 \mu \mathrm{M}$ verapamil (Sigma-Aldrich; Merck KGaA). During the incubation, the tubes were shaken every $20 \mathrm{~min}$ to mix the cells with the solution. The cells were washed twice with Hank's solution, $1 \mu \mathrm{g} / \mathrm{ml}$ propidium iodide (PI; Sigma-Aldrich; Merck KGaA) was added and this was filtered through a $70 \mu \mathrm{m}$ cell strainer (BD Biosciences; Becton, Dickinson and Company). SP cell analysis and sorting were performed using MoFlo XDP (Beckman Coulter, Inc.). The data were analyzed using Summit software version 5.0 (Beckman Coulter, Inc.). Hoechst 33342 was excited with a UV laser at $350 \mathrm{~nm}$ and fluorescence emission was measured with $450 \mathrm{~nm}$ (Hoechst blue) and $570 \mathrm{~nm}$ (Hoechst red) optical filters. PI labeling was measured for the discrimination of dead cells.

Cell viability analysis. The water-soluble tetrazolium salt (WST-1; Roche Diagnostics) assay was used to assess cytotoxicity as described previously (9). Briefly, $4 \times 10^{3}$ cells per well in a 96-well plate were cultured at $37^{\circ} \mathrm{C}$ for $24 \mathrm{~h}$ and incubated with gradient concentrations of cisplatin (Sigma-Aldrich;
Merck KGaA; 0, 2, 4, 8, 16, 32 and $64 \mu \mathrm{M})$, doxorubicin (Sigma-Aldrich; Merck KGaA; 0, 0.5, 1, 1.5, 2, 3 and $4 \mu \mathrm{M}$ ) or $4,4^{\prime}-\operatorname{SAD}(0,0.5,1,1.5,2,3$ and $4 \mu \mathrm{M})$ at $37^{\circ} \mathrm{C}$ for $48 \mathrm{~h}$. Then, cells were treated with $10 \%$ WST-1 reagent for $4 \mathrm{~h}$ at $37^{\circ} \mathrm{C}$ and the optical density at $450 \mathrm{~nm}$ was tested with an ELISA reader (TECAN Infinite M200 Pro; Tecan Group, Ltd.). Each experiment was carried out in triplicate. $\mathrm{The} \mathrm{IC}_{50}$ was calculated using GraphPad Prism software version 7.0 (GraphPad Software, Inc.).

Wound healing assay. The wound healing assay was performed to assess cell motility as described in our previous study (9). $\mathrm{PLC} / \mathrm{PRF} / 5$ and $\mathrm{HuH}-7$ cells $\left(8 \times 10^{5}\right.$ cells/ml) were seeded in 6-well plates and incubated for $24 \mathrm{~h}$ to form confluent cell clusters. The vertical cell wounds were generated by $10 \mu l$ sterile microtips, washed with PBS three times to remove shedding cells and cultured with $2 \mathrm{ml}$ FBS-free DMEM containing different concentrations $(0,0.5$ and $1 \mu \mathrm{M})$ of 4,4'-SAD. Wound closure was observed at 0,24 and $48 \mathrm{~h}$ with an inverted fluorescent microscope (magnification, x100; Nikon Corporation). Each experiment was performed in triplicate.

Transwell assay. Inhibition capacity against cell invasion was assessed using the Millipore 24-well Millicell Chamber with an $8-\mu \mathrm{m}$ pore size (EMD Millipore). Using a standard procedure, the upper of Transwell chambers were coated with Matrigel (BD Biosciences; Becton, Dickinson and Company) at $37^{\circ} \mathrm{C}$ for $1 \mathrm{~h}$ and a $100 \mu \mathrm{l}$ cell suspension containing a total of $2 \times 10^{5}$ cells (previously treated with $0,0.5,1$ and $2 \mu \mathrm{M} 4,4$ '-SAD) in DMEM without FBS were added to the upper chamber. The lower chamber was filled with $600 \mu \mathrm{l}$ DMEM with $20 \%$ FBS. After incubation at $37^{\circ} \mathrm{C}$ for $24 \mathrm{~h}$, the chamber was washed twice with PBS buffer, fixed with precooled $100 \%$ methanol on ice for $15 \mathrm{~min}$ and stained with $0.5 \%$ crystal violet at room temperature for $20 \mathrm{~min}$. In total, five random fields were imaged and the number of invaded cells was counted under a fluorescent microscope (magnification, x400; Nikon Corporation).

Western blot analysis Cells were harvested and lysed with RIPA buffer (Beyotime Institute of Biotechnology). Total protein was quantified using a bicinchoninic acid assay kit (Beyotime Institute of Biotechnology) and $30 \mu \mathrm{g}$ protein/lane was separated with $12 \%$ SDS-PAGE by electrophoresis (Bio-Rad Laboratories, Inc.). The protein sample was transferred to the nitrocellulose membrane, which was blocked with $5 \%$ (w/v) milk-PBS-0.1\%Tween 20 (TBST) at room temperature for $1 \mathrm{~h}$ and incubated with specific primary rabbit antibodies against human (h)ABCG2 (cat. no. 42078S; Cell Signaling Technology, Inc.), hMMP-9 (cat. no. 3852S; Cell Signaling Technology, Inc.), hTIMP-1 (cat. no. 8946S; Cell Signaling Technology, USA), mouse (m)MMP-9 (cat. no. BA2202; Wuhan Boster Biological Technology, Ltd.), mTIMP-1 (cat. no. A00561; Wuhan Boster Biological Technology, Ltd.) and $\beta$-actin (cat. no. 3700; Cell Signaling Technology, Inc.) at 1:1,000 dilutions in $5 \%(\mathrm{w} / \mathrm{v})$ milk-PBST overnight at $4^{\circ} \mathrm{C}$. The membranes were subsequently washed three times, every $10 \mathrm{~min}$, in PBST and incubated with a horseradish peroxidase (HRP)-conjugated anti-rabbit $\operatorname{IgG}$ (1:5,000; cat. no. BA1054; Wuhan Boster Biological Technology, Ltd.) secondary antibody or an 
HRP-conjugated anti-mouse IgG (1:5,000; cat. no. BA1050; Wuhan Boster Biological Technology, Ltd.) secondary antibody at room temperature for $1 \mathrm{~h}$. Protein bands were detected by the FluorChem E digital darkroom system (ProteinSimple). Blots were performed in triplicate and protein expression levels were quantified using ImageJ v.1.8.0 software (National Institutes of Health).

$R N A$ extraction and reverse transcription-quantitative PCR $(R T-q P C R)$ analysis. Total RNA was isolated from cells with TRIzol ${ }^{\oplus}$ reagent (Thermo Fisher Scientific,Inc.) and mRNA was synthesized to cDNA with the GoScript Reverse Transcriptase system (Promega Corporation) at $42^{\circ} \mathrm{C}$ for $1 \mathrm{~h}$. qPCR was subsequently performed using a Light Cycler 480 II (Roche Diagnostics) with the miScript SYBR Green PCR kit (Qiagen $\mathrm{GmbH})$. The following thermocycling conditions were used: Initial denaturation at $95^{\circ} \mathrm{C}$ for $2 \mathrm{~min}$; followed by 40 cycles at $94^{\circ} \mathrm{C}$ for $15 \mathrm{sec}, 55^{\circ} \mathrm{C}$ for $15 \mathrm{sec}$ and $68^{\circ} \mathrm{C}$ for $30 \mathrm{sec}$. The oligonucleotide primer pairs used in this study were as follows: ABCG2 forward, 5'-CAGGTGGAGGCAAATCTTCGT-3' and reverse, 5'-ACCCTGTTAATCCGTTCGTTTT-3'; MMP-9 forward, 5'-CCTGGAGACCTGAGAAC-3' and reverse, 5'-CAGGGACAGTTGCTTCT-3'; TIMP-1 forward, 5'-ACTCTTGCACATCACTACCT-3' and reverse, 5'-CATTACTCACAGTCCCTTTT-3'; and GAPDH forward, 5'-GAAGGTGAAGGTCGGAGTC-3' and reverse, 5'-GAAGATGGTGATGGGATTTC-3'. The relative mRNA expression levels were quantified using the $2^{-\Delta \Delta \mathrm{Cq}}$ method (16).

In vivo H22 intravenous (i.v.) model. To assess the effects of 4,4'-SAD on tumor metastasis in vivo, the present study established a H22 i.v. model. In total, $4 \times 10^{4} \mathrm{H} 22$ cells in $200 \mu \mathrm{l}$ PBS were injected into the tail vein of KM mice. KM mice were randomly divided into four groups ( $\mathrm{n}=8$ for each group) on day 1 . Dry compounds were suspended in $1 \%$ carboxymethylcellulose (CMC)-Na (Sigma-Aldrich; Merck KGaA) for immediate use. Mice were orally gavaged with either $200 \mu \mathrm{l}$ normal 1\% CMC-Na solution (control) or 4,4'-SAD (10, 20 or $40 \mathrm{mg} / \mathrm{kg}$ ) every 2 days from days 2-28. Weight was measured every 4 days until mice were euthanized on day 28 . Contrastive images were captured after eviscerating the mice lungs. Lungs were excised, fixed in $10 \%$ neutral buffered formalin for $24 \mathrm{~h}$ at room temperature, embedded in paraffin, cut into 3-5 $\mu \mathrm{m}$ sections and stained with hematoxylin for $5 \mathrm{~min}$ and eosin for $1 \mathrm{~min}$, both at room temperature. The number of tumor nodules on the lung surface was counted by visual inspection using a magnifying glass and tissues were observed under a fluorescent microscope (magnification, x400; Nikon Corporation).

Immunohistochemistry. Tumor tissues of lungs in KM mice were harvested, fixed in $10 \%$ neutral buffered formalin at room temperature for $24 \mathrm{~h}$, then embedded in paraffin and cut into $3-\mu \mathrm{m}$ thick sections. The sections were blocked with 5\% (w/v) BSA (EMD Millipore) at room temperature for 30 min and incubated with anti-MMP-9 antibody (1:100; cat. no. BA2202; Wuhan Boster Biological Technology, Ltd.) overnight at $4^{\circ} \mathrm{C}$ as previously described (17). Following the primary antibody incubation, the sections were incubated with an HRP-conjugated anti-rabbit IgG secondary antibody (1:500; cat. no. BA1054; Wuhan Boster Biological Technology, Ltd.) at room temperature for $30 \mathrm{~min}$. The expression of MMP-9 was determined with the 3,3-diaminobenzidine assay kit (OriGene Technologies, Inc.), according to the manufacturer's protocol. All sections were imaged using a light microscope (magnification, $\mathrm{x} 400)$.

Statistical analysis. All data are presented as the mean \pm SD of triplicate repeats. All statistical analyses were conducted using a Student's t-test or one-way ANOVA followed by Tukey's test, using SPSS 13.0 software (IBM Corp.). $\mathrm{P}<0.05$ was considered to indicate a statically significant difference.

\section{Results}

4,4'-SAD inhibits the proliferation of SP cells in PLC/PRF/5 and $\mathrm{HuH}-7$. The present study isolated SP and non-SP (NSP) cells from human liver cancer cell lines PLC/PRF/5 and HuH-7 based on the ability of SP cells to actively efflux the Hoechst 33342 dye. To evaluate the cytotoxic effects of 4,4'-SAD and traditional chemotherapy drugs on SP and NSP cells, cells were treated with gradient concentrations of 4,4'-SAD, cisplatin and doxorubicin for $48 \mathrm{~h}$, then cell viability was assessed via the WST-1 assay. It was found that the $\mathrm{IC}_{50}$ values of cisplatin, doxorubicin and 4,4'-SAD were 23.63, 1.731 and $1.871 \mu \mathrm{M}$ in PLC/PRF/5 SP cells and 18.89, 1.894 and $1.088 \mu \mathrm{M}$ in HuH-7 SP cells, respectively (Fig. 1B and C). Therefore, suggesting that SP cells were more sensitive to 4,4'-SAD compared with traditional chemotherapeutic drugs. Furthermore, the $\mathrm{IC}_{50}$ values of cisplatin and doxorubicin were higher in SP cells compared with NSP cells in both cell lines, whereas the $\mathrm{IC}_{50}$ value of $4,4-\mathrm{SAD}$ was lower in SP cells compared with NSP cells (Fig. 1B and C), thus indicating that SP cells were resistant to traditional chemotherapy drugs, but still sensitive to 4,4'-SAD.

The effect of 4,4'-SAD and the traditional chemotherapy drugs, cisplatin and doxorubicin, on the percentage alternation of SP cells was examined in PLC/PRF/5 and HuH-7 cells. It was found that the fraction of SP cells increased from 2.95 to 3.88 and $3.63 \%$, but decreased to $0.95 \%$ in PLC/PRF/5 after the $48 \mathrm{~h}$ treatment of $10 \mu \mathrm{M}$ cisplatin, $1 \mu \mathrm{M}$ doxorubicin and $1 \mu \mathrm{M} 4,4$ '-SAD, respectively (Fig. 1D). Moreover, the fraction of SP cells increased from 2.16 to 3.15 and $3.98 \%$, but decreased to $1.09 \%$ in $\mathrm{HuH}-7$ after $48 \mathrm{~h}$ treatment of $10 \mu \mathrm{M}$ cisplatin, $1 \mu \mathrm{M}$ doxorubicin and $1 \mu \mathrm{M} 4,4$ '-SAD, respectively (Fig. 1D). Collectively, the results demonstrated that 4,4'-SAD inhibited and had cytotoxic effects on SP cells, whereas the traditional chemotherapy drugs cisplatin and doxorubicin had more powerful cytotoxic effects on NSP cells compared with SP cells.

4,4'-SAD inhibits the invasion and migration of SP cells. Besides drug resistance, SP cells are also involved in tumor invasion and metastasis (18). Due to the anti-SP cell efficacy of 4,4'-SAD in vitro, the present study investigated whether 4,4'-SAD could affect the invasion and migration of PLC/PRF/5 and HuH-7 SP cells using wound healing and Transwell assays. The wound healing assay results demonstrated a decrease in the migration of both PLC/PRF/5 and HuH-7 SP cells after treatment with gradient concentrations of 4,4'-SAD for 24 and $48 \mathrm{~h}$ (Fig. 2A). However, 4,4'-SAD was more effective at suppressing of SP cell migration in PLC/PRF/5 cells compared with HuH-7 cells. 
A<smiles>COC(=O)[C@]12Oc3c(-c4ccc(O)c5c4O[C@](C(=O)O)(C(=O)OC)[C@@H](O)[C@H](C)C5)ccc(O)c3C(=O)C1=C(O)C[C@@H](C)[C@H]2O</smiles>

C

\begin{tabular}{ccccccc}
\hline \multirow{2}{*}{ compound } & \multicolumn{2}{c}{$\mathrm{PLC} / \mathrm{PRF} / 5 \mathrm{IC}_{50}$} & & \multicolumn{2}{c}{$\mathrm{HuH}-7 \mathrm{IC}_{50}$} \\
\cline { 2 - 3 } & SP cells & NSP cells & & SP cells & NSP cells \\
\hline DDP & 23.63 & 14.80 & & 18.89 & 11.19 \\
DOX & 1.731 & 1.365 & & 1.894 & 1.307 \\
4,4'-SAD & 1.871 & 2.176 & & 1.088 & 1.609 \\
\hline
\end{tabular}

B
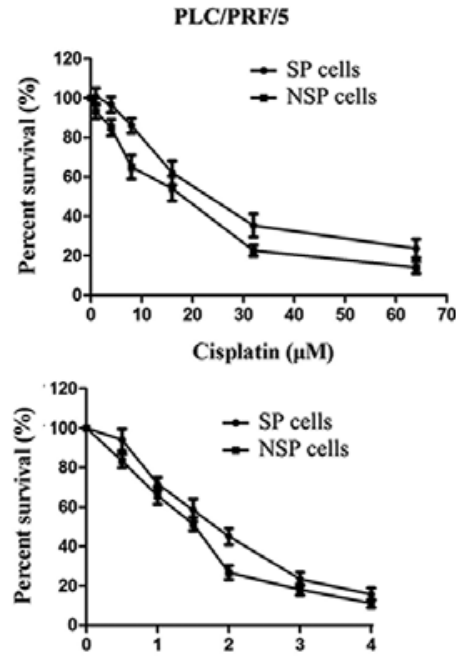

Doxorubicin $(\mu \mathrm{M})$

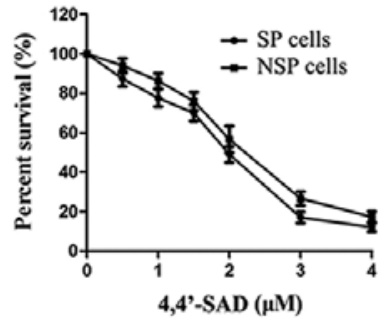

HuH-7
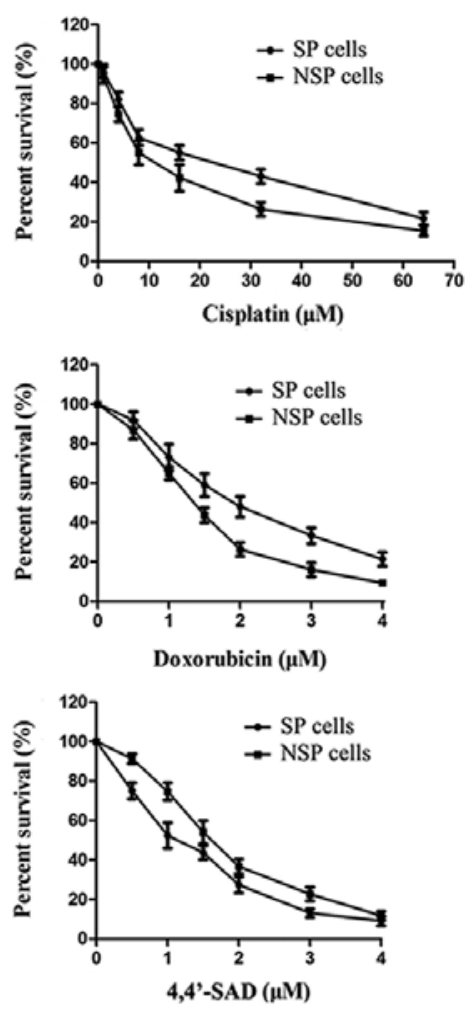

D
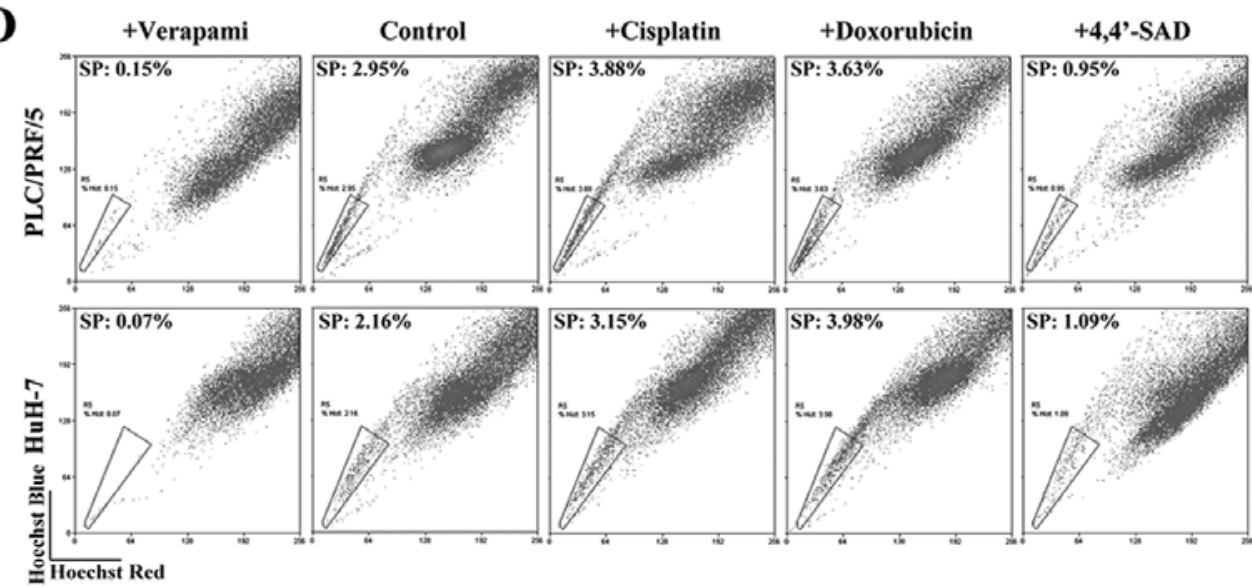

Figure 1. Treatment with 4,4'-SAD inhibits the growth of SP cells obtained from PLC/PRF/5 and HuH-7 cells. (A) Chemical structure of 4,4'-SAD. (B) SP cells were incubated with gradient concentrations of cisplatin, doxorubicin and 4,4'-SAD for $48 \mathrm{~h}$, then the cellular viability of SP and NSP cells was analyzed by water-soluble tetrazolium salt assay. SP and NSP cells were isolated from PLC/PRF/5 and HuH-7 cells by fluorescence activated cell sorting, based on the intensity of Hoechst 33342 staining. Data are presented as the mean $\pm \mathrm{SD}$ of three independent experiments. (C) $\mathrm{IC}_{50}$ of cisplatin, doxorubicin and 4,4'-SAD in SP and NSP cells. SP and NSP cells were isolated from PLC/PRF/5 and HuH-7 cells by fluorescence activated cell sorting, based on the intensity of Hoechst 33342 staining. (D) Percentages of SP cells in PLC/PRF/5 and HuH-7 cells after treatment of $10 \mu \mathrm{M}$ cisplatin, $1 \mu \mathrm{M}$ doxorubicin and $1 \mu \mathrm{M} 4,4^{4}-\mathrm{SAD}$ for $48 \mathrm{~h}$. Verapamil was added as a control. 4,4'-SAD, 4,4'-bond secalonic acid D; SP, side population; NSP, non-side population.

In the Transwell assay, the number of PLC/PRF/5 SP cells passing through the Matrigel per field under an inverted microscope (magnification, x100) was reduced from $203 \pm 13$ to $141 \pm 6,107 \pm 4$ and $86 \pm 5$ after treatment with $0,0.5,1$ and $2 \mu \mathrm{M} 4,4$-SAD for $24 \mathrm{~h}$, respectively. Moreover, the number of invaded HuH-7 SP cells per field decreased from $147 \pm 7$ to $57 \pm 4,28 \pm 5$ and $23 \pm 3$ after treatment with $0,0.5,1$ and $2 \mu \mathrm{M}$ $4,4^{\prime}$-SAD for $24 \mathrm{~h}$, respectively (Fig. 2B). Therefore, it the results indicated that $4,4^{\prime}$-SAD significantly decreased the invasion of PLC/PRF/5 and HuH-7 SP cells.
4,4'-SAD decreases the expression levels of ABCG2 and $M M P-9$ and increases the expression of TIMP-1 in SP cells. To further examine the role of 4,4'-SAD in inhibiting the proliferation, migration and invasion of SP cells, related gene expression levels were measured by western blotting and RT-qPCR. As ABCG2 is an efflux protein and multidrug resistance marker in SP cells, ABCG2 expression was assessed and it was found that 4,4'-SAD reduced the protein and mRNA expression levels of ABCG2 in SP cells in a concentration-dependent manner (Fig. 3A). The results also 
A
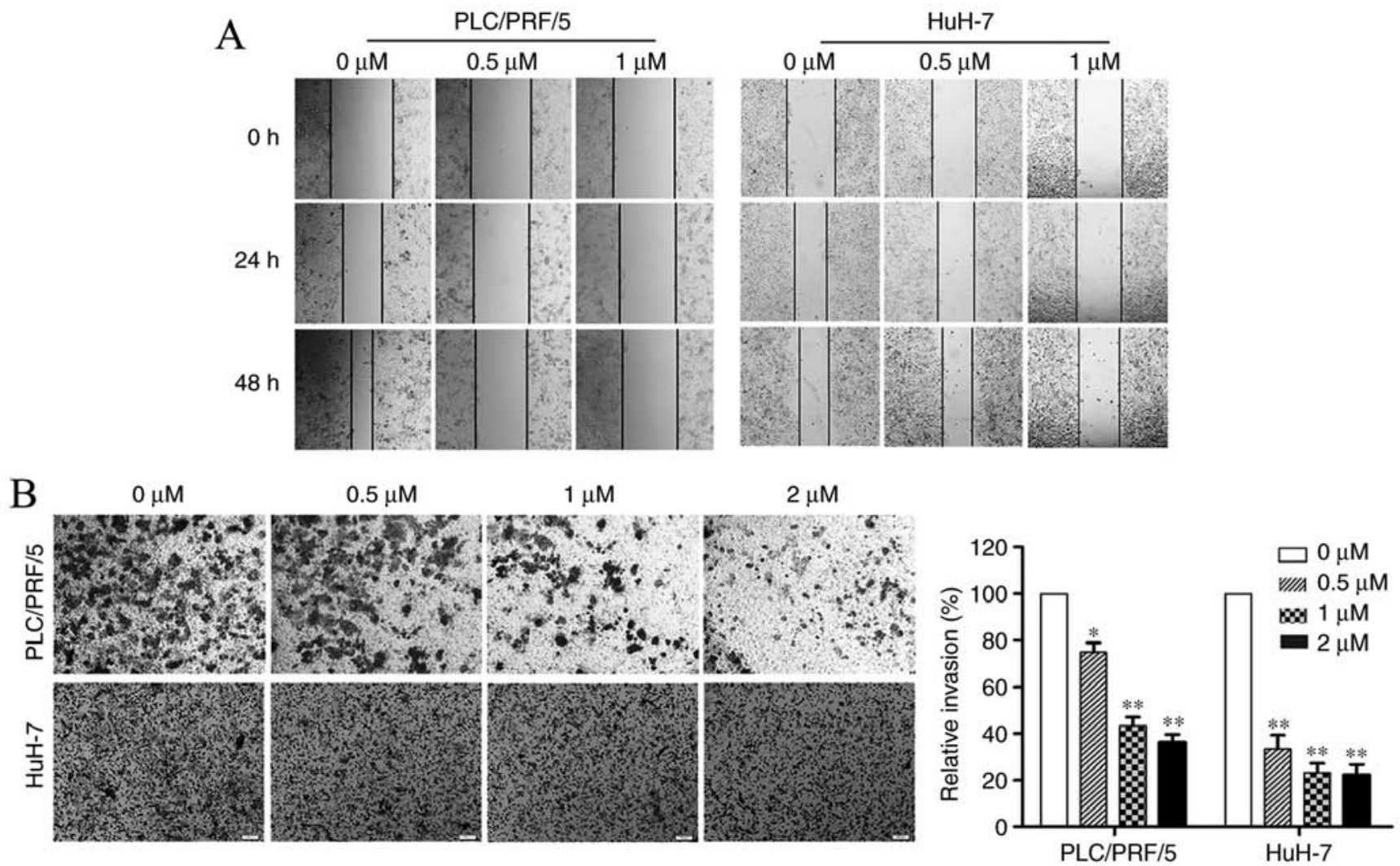

Figure 2. Treatment with 4,4'-SAD inhibits the migratory and invasive capacity of PLC/PRF/5 and HuH-7 side population cells in vitro. (A) Wound healing assay was performed in PLC/PRF/5 and HuH-7 cells treated with 4,4'-SAD $(0,0.5$ and $1 \mu \mathrm{M})$ for 0,24 and 48 h. Magnification, x100. (B) Cell invasion was measured by the Transwell assay and quantitatively analyzed after treating cells with 4,4'-SAD $(0,0.5,1$ and $2 \mu \mathrm{M})$ for $24 \mathrm{~h}$. ${ }^{*} \mathrm{P}<0.05$ and ${ }^{* *} \mathrm{P}<0.01 \mathrm{vs} .0 \mu \mathrm{M}$. 4,4'-SAD, 4,4'-bond secalonic acid D. Magnification, x400.

indicated that 4,4'-SAD treatment downregulated the expression of MMP-9 at both the protein and mRNA levels, and upregulated the expression of TIMP-1, an inhibitor of MMP-9, in a dose-independent manner (Fig. 3B). Thus, the results suggested that 4,4'-SAD inhibited metastasis by reducing the proteolytic degradation of the extracellular matrix (ECM) and basement membrane near the tumor.

Effects of 4,4'-SAD on metastasis in vivo. The antimetastatic efficacy of 4,4'-SAD was further assessed using the H22 HCC model in mice. Firstly, the present study investigated whether the role of 4,4'-SAD on metastasis in murine H22 cells was the same as in human PLC/PRF/5 and HuH-7 cells in vitro. It was found that 4,4'-SAD attenuated the expression of MMP-9 and enhanced the expression of TIMP-1 in H22 cells (Fig. S1), which indicated that 4,4'-SAD inhibited the metastasis of mouse $\mathrm{H} 22$ cells by regulating MMP-9 and TIMP-1.

The mouse model was constructed by injecting $\mathrm{H} 22$ into the tail vein of $\mathrm{KM}$ mice at $4 \times 10^{4}$ cells in $200 \mu \mathrm{l}$ PBS. Then, mice were orally gavaged with either normal CMC-Na (control) or 4,4'-SAD (10, 20 or $40 \mathrm{mg} / \mathrm{kg}$, every other day) from days 2-28 and were euthanized on day 28 (Fig. 4A). The results suggested that mice treated with 4,4'-SAD exhibited less lung metastatic loci compared with mice in the control group (Fig. 4B and C). Moreover, no significant reduction in body weight change was observed after 4,4'-SAD treatment (Fig. 4D). Histological examinations, which identified the presence of HCC cells in the lung parenchyma, demonstrated the presence of metastasis (Fig. 4E). Furthermore, immunohistochemical staining indicated that MMP-9 expression in lung tissues was inhibited in a dose-independent manner, which was consistent with the experimental results at the cellular level (Fig. 4E). Collectively, these results suggested that 4,4'-SAD efficiently suppressed lung metastasis without obvious side effects in vivo.

\section{Discussion}

HCC is an often fatal malignant tumor type with a high recurrence rate, poor prognosis and chemoresistance (19). Despite advances in anticancer therapies such as chemotherapy, radiotherapy and targeted therapies, the survival rate of HCC remains poor (20). Moreover, CSC-mediated relapse and metastasis have been identified as key factors in reducing the efficacy of current anticancer cytotoxic therapies (3). Our previous study showed that 4,4'-SAD, a mycotoxin from the secondary metabolites of $P$. oxalicum, promotes apoptosis of tumor cells in the human HCC cell lines PLC/PRF/5 and HuH-7 by activating apoptosis-related protein expression, as well as regulating the $\mathrm{Bax} / \mathrm{Bcl}-2$ ratio (9). The present results suggested that 4,4'-SAD exhibited potent anti-CSC activity by inhibiting the growth and metastasis of SP cells, which was regulated by ABCG2 and MMP-9 in vitro and in vivo. Therefore, the results may facilitate the potential application of 4,4'-SAD in future liver cancer therapy. 
A
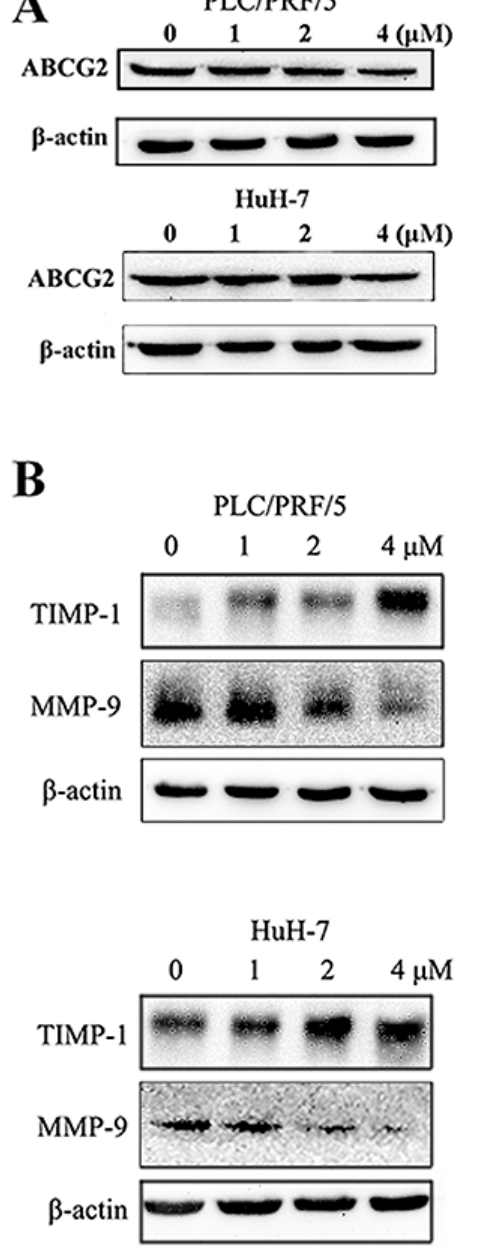
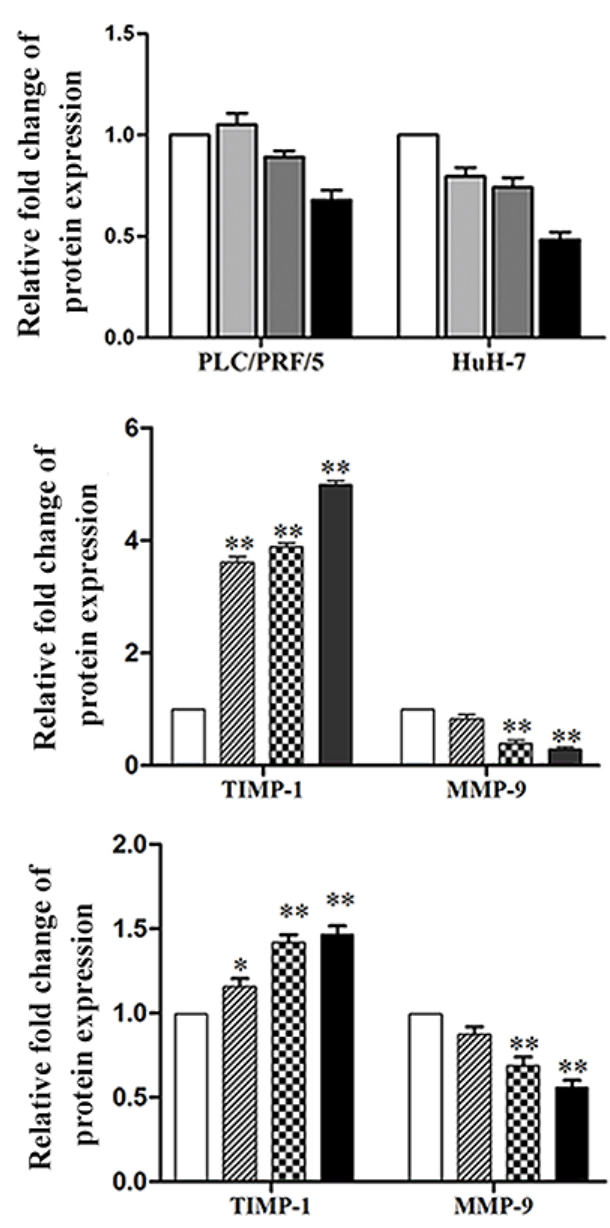
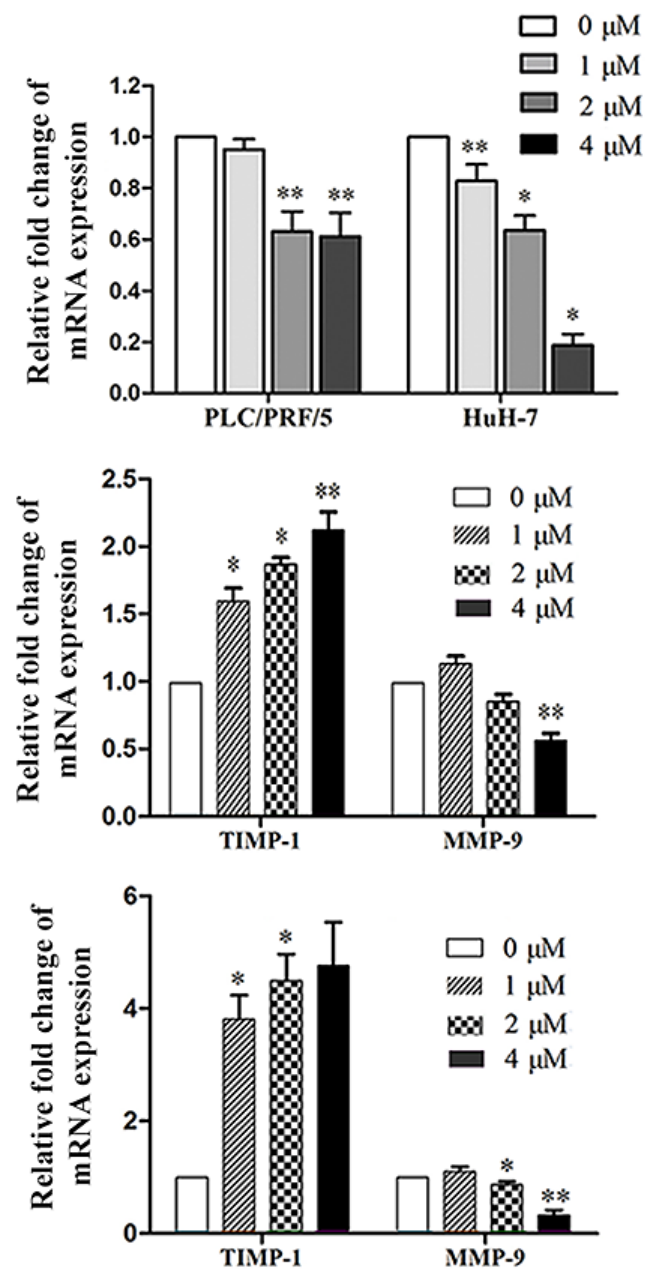

Figure 3. Treatment with 4,4'-SAD increases the expression of TIMP-1 and reduced the expression levels of ABCG2 and MMP-9. (A) Western blotting and RT-qPCR analyses of ABCG2 expression in PLC/PRF/5 and HuH-7 SP cells treated with the indicated concentrations $(0-4 \mu \mathrm{M})$ of $4,4^{4}-\mathrm{SAD}$ for $48 \mathrm{~h}$. $\beta$-actin was used as a loading control. (B) Expression levels of MMP-9 and TIMP-1 in PLC/PRF/5 and HuH-7 SP cells treated with 4,4'-SAD were detected by western blotting and RT-qPCR. Data are presented as the mean $\pm \mathrm{SD}$. $\mathrm{N}=3 .{ }^{*} \mathrm{P}<0.05,{ }^{* *} \mathrm{P}<0.01$ vs. control group $(0 \mu \mathrm{M})$. RT-qPCR, reverse transcription-quantitative PCR; 4,4'-SAD, 4,4'-bond secalonic acid D; MMP, matrix metalloproteinase; TIMP-1, tissue inhibitors of metalloproteinases; ABCG2, ATP-binding cassette superfamily G member 2 .

The present results indicated that 4,4'-SAD may have significant direct cytotoxicity on SP cells, as it was found that SP cells were resistant to the traditional chemotherapeutic drugs cisplatin and doxorubicin, but were sensitive to 4,4'-SAD. In addition, the $\mathrm{IC}_{50}$ values of cisplatin and doxorubicin in SP cells were higher compared with NSP cells, whereas SP cells were more sensitive to 4,4'-SAD compared with NSP cells. SP cells, which are involved in multidrug resistance and tumor initiation, express high levels of $A B C$ transporters, including ABCG2, to expulse Hoechst 33342 dye $(4,21)$. Moreover, previous studies have revealed that SAD reduces the expression of $\mathrm{ABCG} 2$ and percentage of SP cells in lung cancer cells $(13,14)$. The present results demonstrated that $4,4^{\prime}-\mathrm{SAD}$, as the analog of SAD, targeted SP cells and regulated $\mathrm{ABCG} 2$ expression. Therefore, it was speculated that the potential of 4,4'-SAD to reverse the drug resistance of SP cells may be partially due to its inhibition of ABCG2. Furthermore, SAD induces the degradation of ABCG2 by activating calpain-1 $(13,14)$, and thus, 4,4 '-SAD may regulate $\mathrm{ABCG} 2$ via the same pathway. However, further research is required to elucidate the detailed mechanism involved.
Self-renewing CSCs are usually associated with the course of metastatic disease (22). Metastasis is a primary obstacle to successful cancer therapy and is closely linked to the rates of morbidity and mortality in liver cancer types $(3,23)$. As 4,4 '-SAD showed high cytotoxic effects on SP cells, investigating its role in tumor progression and metastasis inhibition may be valuable $(24,25)$. The present results indicated that 4,4'-SAD suppressed migration and invasion by downregulating the expression of MMP-9 and upregulating the expression of TIMP-1 at both protein and mRNA levels in vitro. Moreover, 4,4'-SAD reduced lung metastatic loci in a lung metastatic model of H22 HCC without side effects. MMP-9, which is an important MMP in the degradation of multiple elements of the ECM, facilitates the release of numerous prometastatic factors, such as vascular endothelial growth factor $\mathrm{A}$, transforming growth factor- $\beta$, tumor necrosis factor- $\alpha$ and interleukin- 8 , leading to the migration of cancer cells to other tissues (26-28). However, the activities of MMPs may be limited by their associated tissue inhibitors of metalloproteinases, which inhibit tumor growth and invasion (29). In addition, both 

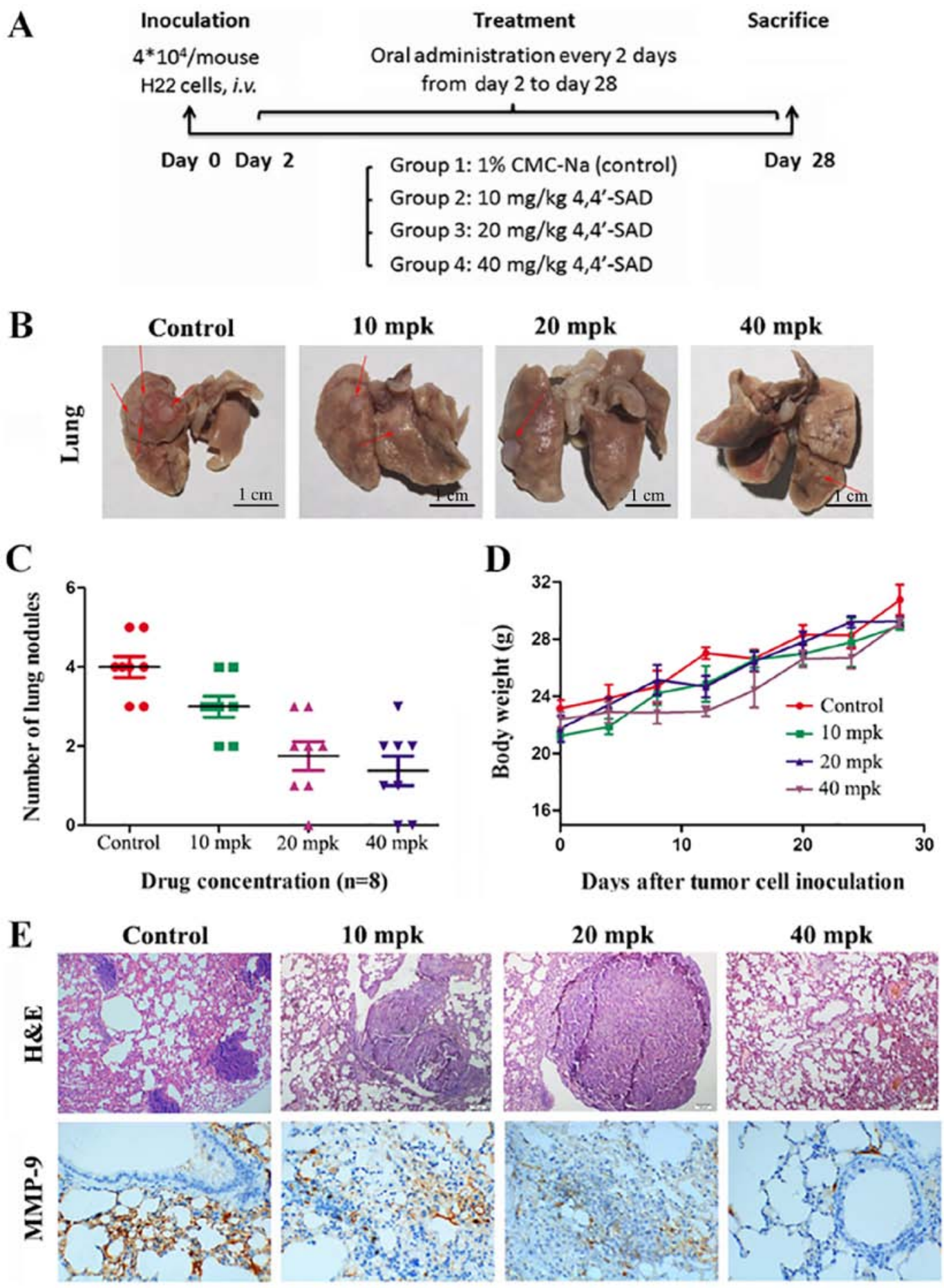

Figure 4. Treatment with 4,4'-SAD inhibits tumor metastases in vivo. (A) Schematic of the experimental protocol. (B) Images of mouse lung inoculated with H22 cells via tail-vein injection. (C) Metastatic tumor nodule number in the lung metastasis model. (D) Body weights measured every 4 days. (E) H\&E staining and MMP-9 immunohistochemistry of metastatic tumors in the lungs of mice. Magnification, $\mathrm{x} 400$. H\&E, hematoxylin and eosin; MMP, matrix metalloproteinase; 4,4'-SAD, 4,4'-bond secalonic acid D; mpk, milligrams per kilogram.

CSCs and the equilibrium between the content of MMP-9 and TIMP-1 play important roles in the pathogenesis of tumor metastasis (29-32).

In conclusion, the present results suggested 4,4'-SAD had effects on advanced liver cancer. Mechanistically, 4,4 '-SAD significantly suppressed the growth of SP cells in $\mathrm{PLC} / \mathrm{PRF} / 5$ and $\mathrm{HuH}-7$ cells via the downregulation of ABCG2. In addition, it was found that 4,4'-SAD reduced the migration and invasion of tumor cells both in vitro and in vivo, via MMP-9 and TIMP-1. Combined with previous studies, the present results indicated that 4,4'-SAD may be a novel therapeutic agent to treat liver cancer cells that are resistant to current therapies and are also responsible for relapse and metastasis.

\section{Acknowledgements}

Not applicable. 


\section{Funding}

The present study was funded by the Joint Funds for the Innovations of Science and Technology, Fujian Province (grant no. 2017Y9075), Key Scientific Project of Ministry of Education in Fujian Province (grant no. JZ160419), Natural Science Foundation of Fujian Province (grant nos. 2017J01855 and 2017J01179), Leading Project Foundation of Fujian Province (grant no. 2018Y0015), 'Young Top Creative Talents' of the Second Batch Special Support 'Double Hundred Plan' of Fujian Province and Science and Technology Program of Fujian Province, China (grant no. 2018Y2003).

\section{Availability of data and materials}

The datasets used and/or analyzed during the present study are available from the corresponding author on reasonable request.

\section{Authors' contributions}

QL contributed to the design of this study. LC, MC, YL and SL performed the experiments. LC and QZ analyzed and interpreted the experimental data and wrote the manuscript. QL revised the manuscript. All authors read and approved the final manuscript.

\section{Ethics approval and consent to participate}

All experiments involved in this study were approved by both the Institutional Review Boards of Fuzhou University and the Ethics Committee of Fujian Cancer Hospital.

\section{Patient consent for publication}

Not applicable.

\section{Competing interests}

The authors declare that they have no competing interests.

\section{References}

1. Bray F, Ferlay J, Soerjomataram I, Siegel RL, Torre LA and Jemal A: Global cancer statistics 2018: GLOBOCAN estimates of incidence and mortality worldwide for 36 cancers in 185 countries. CA Cancer J Clin 68: 394-424, 2018.

2. Wu S, Du R, Gao C, Kang J, Wen J and Sun T: The role of XBP1s in the metastasis and prognosis of hepatocellular carcinoma. Biochem Biophys Res Commun 500: 530-537, 2018.

3. Terada $\mathrm{T}$ and Maruo H: Unusual extrahepatic metastatic sites from hepatocellular carcinoma. Int J Clin Exp Pathol 6: 816-820, 2013.

4. Wolmarans E, Nel S, Durandt C, Mellet J and Pepper MS: Side population: Its use in the study of cellular heterogeneity and as a potential enrichment tool for rare cell populations. Stem Cells Int 2018: 2472137, 2018.

5. Zhou S, Schuetz JD, Bunting KD, Colapietro AM, Sampath J, Morris JJ, Lagutina I, Grosveld GC, Osawa M, Nakauchi H, et al: The $\mathrm{ABC}$ transporter Bcrp1/ABCG2 is expressed in a wide variety of stem cells and is a molecular determinant of the side-population phenotype. Nat Med 7: 1028-1034, 2001.

6. Toyoda Y, Takada T and Suzuki H: Inhibitors of human ABCG2: From technical background to recent updates with clinical implications. Front Pharmacol 10: 208, 2019.
7. Choi $\mathrm{YH}$ and $\mathrm{Yu} \mathrm{AM}$ : $\mathrm{ABC}$ transporters in multidrug resistance and pharmacokinetics, and strategies for drug development. Curr Pharm Des 20: 793-807, 2014.

8. Najafi M, Farhood B and Mortezaee K: Cancer stem cells (CSCs) in cancer progression and therapy. J Cell Physiol 234: 8381-8395, 2019.

9. Chen L, Li YP, Li XX, Lu ZH, Zheng QH and Liu QY: Isolation of 4,4'-bond secalonic acid D from the marine-derived fungus Penicillium oxalicum with inhibitory property against hepatocellular carcinoma. J Antibiot (Tokyo) 72: 34-44, 2019.

10. Steyn PS: The separation and detection of several mycotoxins by thin-layer chromatography. J Chromatogr A 45: 473-475, 1969.

11. Guru SK, Pathania AS, Kumar S, Ramesh D, Kumar M, Rana S, Kumar A, Malik F, Sharma PR, Chandan BK, et al: Secalonic acid-D represses HIF1 $\alpha /$ VEGF-mediated angiogenesis by regulating the Akt/mTOR/p70S6K signaling cascade. Cancer Res 75: 2886-2896, 2015.

12. Zhang JY, Tao LY, Liang YJ, Yan YY, Dai CL, Xia XK, She ZG, Lin YC and Fu LW: Secalonic acid D induced leukemia cell apoptosis and cell cycle arrest of G(1) with involvement of GSK-3beta/beta-catenin/c-Myc pathway. Cell Cycle 8: 2444-2450, 2009.

13. Zhang H, Huang L, Tao L, Zhang J, Wang F, Zhang X and Fu L: Secalonic acid D induces cell apoptosis in both sensitive and ABCG2-overexpressing multidrug resistant cancer cells through upregulating c-Jun expression. Acta Pharm Sin B 9: 516-525, 2019.

14. Hu YP, Tao LY, Wang F, Zhang JY, Liang YJ and Fu LW: Secalonic acid D reduced the percentage of side populations by down-regulating the expression of ABCG2. Biochem Pharmacol 85: 1619-1625, 2013.

15. National Research Council: Guide for the Care and Use of Laboratory Animals: 8th edition. The National Academies Press, Washington, DC, 2011.

16. Livak KJ and Schmittgen TD: Analysis of relative gene expression data using real-time quantitative PCR and the 2(-Delta Delta C(T)) Method. Methods 25: 402-408, 2001.

17. Kunnumakkara AB, Diagaradjane P, Anand P, Harikumar KB, Deorukhkar A, Gelovani J, Guha S, Krishnan S and Aggarwal BB: Curcumin sensitizes human colorectal cancer to capecitabine by modulation of cyclin D1, COX-2, MMP-9, VEGF and CXCR4 expression in an orthotopic mouse model. Int J Cancer 125: 2187-2197, 2009

18. Wellner UF, Hopt UT and Brabletz T: Tumour stem cells and metastasis. Zentralbl Chir 135: 318-322, 2010 (In German).

19. Gravitz L: Liver cancer. Nature 516: S1, 2014.

20. Parisod L, Duran R, Denys A and Digklia A: Treatment of advanced hepatocellular carcinoma: Novel agents and role of local therapy. Rev Med Suisse 13: 1032-1034, 2017 (In French).

21. Challen GA and Little MH: A side order of stem cells: The SP phenotype. Stem Cells 24: 3-12, 2006.

22. McClements L, Annett S, Yakkundi A, O'Rourke M, Valentine A, Moustafa N, Alqudah A, Simões BM, Furlong F, Short A, et al: FKBPL and its peptide derivatives inhibit endocrine therapy resistant cancer stem cells and breast cancer metastasis by downregulating DLL4 and Notch4. BMC Cancer 19: 351, 2019.

23. Altekruse SF, Henley SJ, Cucinelli JE and McGlynn KA: Changing hepatocellular carcinoma incidence and liver cancer mortality rates in the United States. Am J Gastroenterol 109: 542-553, 2014.

24. Zhang S, Zhang E, Long J, Hu Z, Peng J, Liu L, Tang F, Li L, Ouyang $\mathrm{Y}$ and Zeng $\mathrm{Z}$ : Immune infiltration in renal cell carcinoma. Cancer Sci 110: 1564-1572, 2019.

25. Nandy SB and Lakshmanaswamy R: Cancer stem cells and metastasis. Prog Mol Biol Transl Sci 151: 137-176, 2017.

26. Ward MP and Spiers JP: Protein phosphatase 2A regulation of markers of extracellular matrix remodelling in hepatocellular carcinoma cells: Functional consequences for tumour invasion. Br J Pharmacol 174: 1116-1130, 2017.

27. Zhou R, Xu L, Ye M, Liao M, Du H and Chen H: Formononetin inhibits migration and invasion of MDA-MB-231 and 4T1 breast cancer cells by suppressing MMP-2 and MMP-9 through PI3K/AKT signaling pathways. Horm Metab Res 46: 753-760, 2014.

28. McCawley LJ and Matrisian LM: Matrix metalloproteinases: Multifunctional contributors to tumor progression. Mol Med Today 6: 149-156, 2000.

29. Giusca SE, Caruntu ID, Amalinei C and Avadanei ER: Prognostic significance of MMP-9 and TIMP-1 in liver metastases. Romanian journal of morphology and embryology =. Rev Roum Morphol Embryol 56: 357-364, 2015. 
30. Ogata Y, Ookita A and Kakegawa T: Significance of MMP-9 and TIMP-1 production during liver metastasis in colorectal cancer. Nihon Rinsho 53: 1811-1815, 1995 (In Japanese).

31. Wang D, Plukker JTM and Coppes RP: Cancer stem cells with increased metastatic potential as a therapeutic target for esophageal cancer. Semin Cancer Biol 44: 60-66, 2017.
32. Agliano A, Calvo A and Box C: The challenge of targeting cancer stem cells to halt metastasis. Semin Cancer Biol 44: 25-42, 2017. 